IFP and sc fat. These data indicate that IFP could contribute to the pathophysiological processes in knee OA, possibly through the release of inflammatory mediators.

\section{A121 IMMUNOLOGICAL CHARACTERISATION OF HOFFA'S FAT PAD IN OSTEOARTHRITIS}

E Yusuf, K A Marijt, G J V M van Osch, A Zuurmond, V Stoianovic-Susulic, RE M Toes, M Kloppenburg, A loan-Facsinay Department of Rheumatology, Leiden University Medical Centre, The Netherlands

\subsection{6/ard.2010.129635m}

Obesity is an increasing health problem in the western world. Accumulating data indicate that the adipose tissue is not only a lipid storage site, but also secretes a large number of inflammatory mediators that have powerful immunomodulatory effects. Among others, obesity has been associated with different severity outcomes in rheumatoid arthritis and osteoarthritis. To gain insight into the possible mechanisms underlying this intriguing observation, we have characterised the immune cell composition and release of inflammatory mediators by the infrapatellar fat pad (IFP), an intra-articular adipose organ located in the knee, in the vicinity of synovium and cartilage. We have compared IFP with thigh subcutaneous (sc) adipose tissue from osteoarthritis patients that underwent total knee replacement surgery. Extensive FACS analyses showed the presence of a variety of immune cells in both adipose tissues, CD14 macrophages being the most abundant. The IFP contained a higher percentage of macrophages compared to sc tissue. This also correlated positively with BMI. Moreover, luminex analyses revealed a striking difference in pro-inflammatory cytokine/adipokine secretion between the 